\title{
Effects of Aggregate Grading and Admixture/Filler on Self-Consolidating Concrete
}

\author{
Arka Bhattacharya, Indrajit Ray* and Julio. F. Davalos
}

Department of Civil and Environmental Engineering, West Virginia University, Morgantown, 26506-6103, USA

\begin{abstract}
Self-consolidating concrete (SCC) is becoming a popular choice in concrete industry due to ease of placement in congested reinforcements, reduced labor and equipment, nonsegregating character, and smooth surface. Due to its sensitivity to aggregate grading, proportions, admixtures, and filler contents and being a relatively new material, more information are required on the effects of aggregate grading, mineral admixture types, and fillers on fresh and strength properties.

In this paper a total of $10 \mathrm{SCC}$ were investigated to compare the effects of aggregate size and distribution, mineral admixture, and filler on fresh properties through slump-flow, J-ring, L-box, column segregation, and compressive strength tests. Results show that combined aggregate distribution is critical for selecting proper SCC mixtures. Water/powder ratio and paste volume has more effects on SCC than water-cementitious material ratio. In general SCC properties can be greatly influenced by admixture types and dosage, and filler.
\end{abstract}

Keywords: Admixtures, Aggregate grading, Fillers, Fresh properties, Paste, Powder.

\section{INTRODUCTION}

Self-consolidating concrete (SCC) as defined by ACI 237R-07, is a highly flowable concrete which do not segregate and can spread into place, fill the formwork with heavily congested reinforcement, and encapsulate the reinforcement without any mechanical vibration [1]. Okamura in Japan first proposed the necessity of SCC in 1986 to cater for the reduction in skilled workers in Japan's construction industry and to achieve a durable structure independent of the quality of construction work. After its introduction in late 1980's application of Self-consolidating concrete had been increased in a huge scale because of its several advantages over normal concrete. High workability, reduced labor and equipment, faster and less noisy construction, energy efficiency, flowability through highly congested reinforcements are some of the advantages. Another important benefit of SCC is that it provides improved surface appearance and aesthetics in finished concrete. Pour lines, bug holes, honeycombs, and other surface imperfections are largely reduced by the use of SCC [2]. It has been used in many construction applications such as building, bridge, tunnel construction in many European countries and Japan. However, in the United States the scope of application of SCC was limited and mainly confined in the precast concrete industry until recently. Growing interests are noticed in USA for SCC for which many organizations and agencies like State Departments of Transportation, FHWA, Precast/Presterssed Concrete Institute (PCI) and American Concrete Institute (ACI) are actively working towards implementing SCC in different construction applications [3].

\footnotetext{
*Address correspondence to this author at the Department of Civil and Environmental Engineering, West Virginia University, Morgantown, 265066103, USA; Tel: (304)293-3031; Fax: (304)293-7109;

E-mail: indrajit.ray@mail.wvu.edu
}

Consistent with this trend, a study is undertaken for the development and evaluation of fresh and cracking properties of SCC using locally available crushed limestone and sand as an aggregate, fly ash and slag from local plants, commercial admixtures including silica fume and limestone powder. As properties of SCC vary greatly due to aggregate type, gradation; mineral and chemical admixtures types and dosage, a total of 10 SCC mixtures were prepared using various combinations of aggregates and admixtures. This paper will evaluate and compare the fresh properties and compressive strength of various SCC mixtures developed with different combinations of aggregate, mineral admixtures, and filler. The aggregate gradations will also be compared with the developed combined aggregate gradation optimized for concrete workability, economy and strength by Shilstone [4] for normal concrete.

\section{MIXTURE DESIGN AND EXPERIMENTAL PRO- GRAM}

SCC can be produced with the same materials as of normal concrete and using some special type of admixtures such as viscosity modifying admixtures (VMA) and high-range water reducing admixtures (HRWRA) in some cases. But unlike the ordinary concrete, the mix design and fresh and hardened properties of SCC are much more sensitive to variability of the quality and consistency of the mixture components. To produce a highly flowable concrete with a good resistance against segregation, the amount of coarse aggregate has to be less than that of normal concrete and the reduced part to be replaced by the finer particles. As cement is an expensive and energy consuming material, fillers like limestone powder and mineral admixtures such as slag, silica fume, fly-ash are widely used as partial replacements for SCC production [5,6]. Though the cement replacements with incorporation of non-cementitious fillers in SCC has not 
been a popular choice in North America, the cost of SCC can be reduced through partial substitutions of cement with readily available inert materials such as fillers and limestone powder [7]. As noted by Heirman et al. [5], the influence of filler characteristics on fresh properties is not clear because of the high influence of the superplasticizer and the combined effect of filler and admixtures on the rheology of the paste. Also, depending on the filler type, the SCC mixtures had a higher or comparable compressive strength in comparison with the traditionally vibrated concrete with the same water to cementitious material $(\mathrm{w} / \mathrm{cm})$. A commercially available Type-I Portland cement was used for all mixtures. The slag (SL) and fly ash (FA) used in this study were locally available and conformed to relevant ASTM standards. A commercially available silica fume (SF) and limestone powder ( $87.1 \%$ passing 325 mesh) was used as a pozzolanic and filler material, respectively. Commercially available water reducing admixtures and polycarboxylate based highrange water reducing admixtures (HRWRA) conforming to ASTM C 494/ C 494M were used. Commercial viscosity modifying admixtures were used. Two types of locally available coarse aggregates (CA) of maximum size $25 \mathrm{~mm}$ and $9.5 \mathrm{~mm}$, respectively and $4.75 \mathrm{~mm}$ graded sands were used at different proportions in order to achieve various aggregate gradations. The mixture proportions are shown in Table $\mathbf{1}$.
In Table 1 the mixtures are designated as follows: For example, SCC 1 consists of $35 \%$ of $25 \mathrm{~mm} \mathrm{CA}, 15 \%$ of 9.5 $\mathrm{mm} \mathrm{CA}$ and $50 \%$ of sand by weight of total aggregates, and limestone powder. The above combination is designated as 0.35/0.15/0.50/LP. Similar designations were followed for other mixtures. SCC 1 through SCC 3 consisted of limestone powder (LP) with different combinations of coarse and fine aggregates. The mixtures SCC 4 through SCC 7 consisted of slag + silica fume and different aggregate gradations. SCC 8 through 10 consisted of FA + SF and with different aggregate gradations. Air-entraining agent and water-reducing admixtures were added to all the mixtures with a quantity of $0.39 \mathrm{~kg} / \mathrm{m}^{3}$ and $1 \mathrm{~kg} / \mathrm{m}^{3}$, respectively. VMA used in the studies varied between 0.67 to $1.33 \mathrm{~kg} / \mathrm{m}^{3}$ of concrete. The mix designs were developed by following guidelines given in the report by ACI Committee 237 [1] and referring to well established literatures. As a starting point, it was assumed that $50 \%$ of the total concrete volume should be filled with the bulk volume of coarse aggregate [8]. The powder content for the mixtures were between $450-500 \mathrm{~kg} / \mathrm{m}^{3}$, where powder included cement, fly ash, slag, limestone fillers, materials crushed to less than $0.125 \mathrm{~mm}$ (No. 100 sieve), which is suggested for a slump flow of greater than $650 \mathrm{~mm}$. The other parameters were also kept in the permissible range, for example, paste fraction (calculated on volume) were kept between 34 to $40 \%$ of total mixture volume, mortar fraction

Table 1. Mixture Proportions for $1 \mathbf{~ m}^{3}$ of SCC (All the Values are in Kilograms)

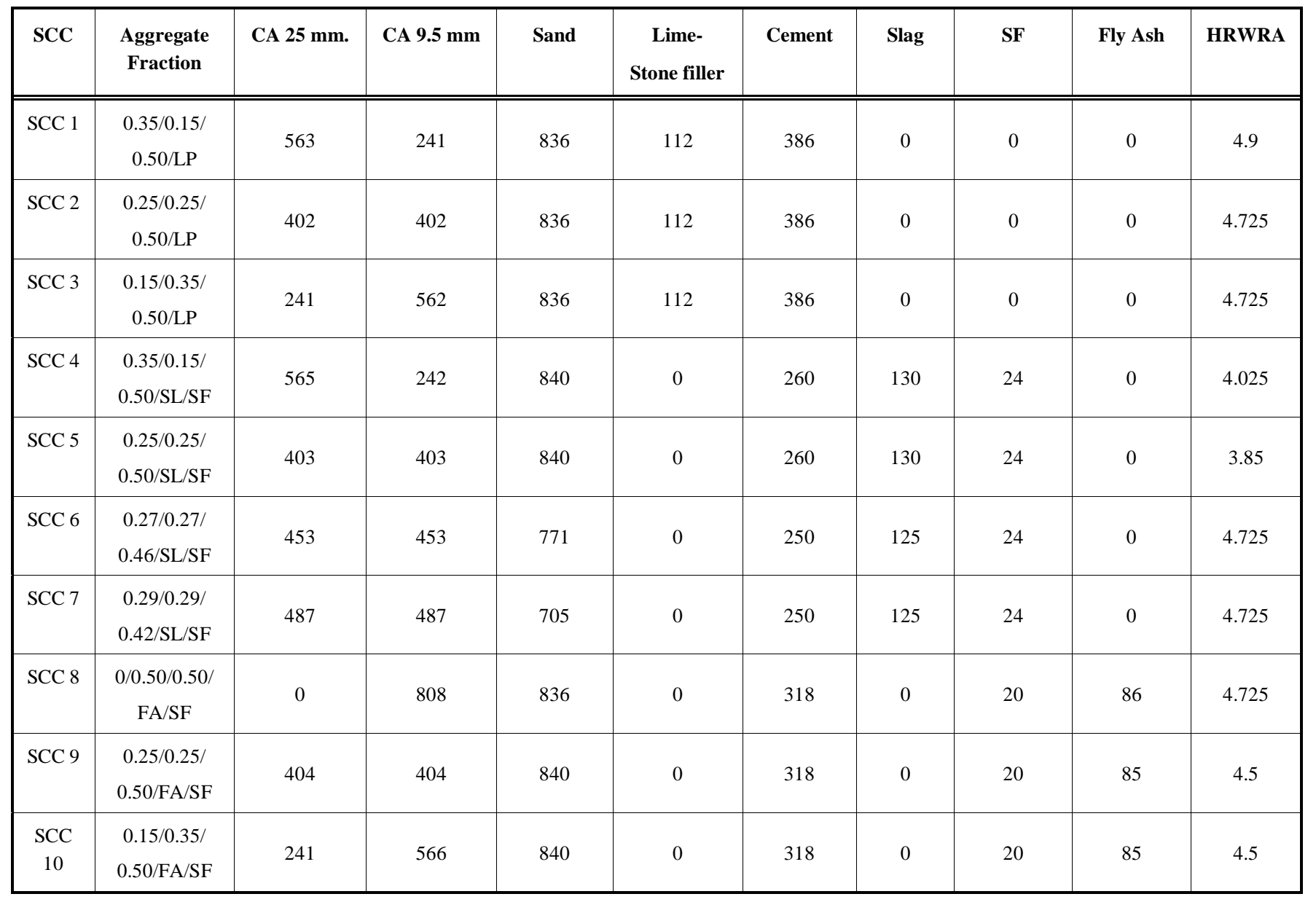


were between 68 to $72 \%$ of total mixture volume and absolute volume of coarse aggregate were between 28 to $32 \%$ (>12 mm nominal maximum size). As the fluctuations in gradation of aggregates and free moisture content can have dramatic influence on the stability of SCC mixtures [9-11], the moisture content of aggregates were maintained strictly and surface moisture quantities were subtracted from the total water quantity to keep the $w / \mathrm{cm}$ ratios constant. As the level of fluidity has a direct impact on the stability of the mixture, once a suitable mixture has been developed the fluidity level at which the mixture becomes unstable was determined $[10,12]$. It was done using the variable dosage of HRWRA to get fluid yet stable mixtures.

The w/cm ratios for all the mixtures were 0.40 except two mixtures which had w/cm ratio of 0.39 and 0.41 , respectively. The CA/FA ratios were kept constant at 0.96 for all the SCC mixtures except for SCC 6 and SCC 7 which had a ratio of 1.18 and 1.38 , respectively. For the mixing a nontilting horizontal axis variable speed laboratory mix was used. All the mixing was completed within 10 minutes. For brevity the mixing sequence is not mentioned here.

The fresh concrete tests performed were (a) slump flow test according to ASTM C 1611/C 1611M-05 for flowability (b) J-ring conforming to ASTM C 1621/C 1621M-06 for passing ability (c) column segregation test according to ASTM C 1610/C 1610M-06 for static segregation, and (d) Lbox test according to "The European Guidelines for Self Compacting Concrete" Annex B.3 [13] for passing ability. For each mixture, eight 100-mm diameter and 200-mm height cylindrical specimens were made without vibration to determine compressive strength. The specimens were demolded after one day of casting and cured at $23^{\circ} \mathrm{C}$ under lime saturated water until day of testing at 7 and 28 days. Four specimens were tested for each mixture at each age and the mean value was reported.

\section{TEST RESULTS AND DISCUSSION}

\section{Effects of Aggregate Gradation}

Aggregate gradation is of utmost importance for successful production and quality control for SCC. As it contains different graded aggregates (course and fine), a combined aggregate gradation curve is more appropriate. Fig. (1) represents the combined aggregate grading curves made with various combinations of $25 \mathrm{~mm}$ coarse aggregate, $9.5 \mathrm{~mm}$ coarse aggregate, sand for different SCC. The combined aggregate gradation was differentiated by particle size ranges: material equal to and larger than $9.5 \mathrm{~mm}$ (designated as "Q" for quality filter), material smaller than $9.5 \mathrm{~mm}$ and retained on $2.36 \mathrm{~mm}$ (designated as "I" for Intermediate particle) and material smaller than $2.36 \mathrm{~mm}$ (designated as "W"). The larger particles related to strength, intermediate particles are related to mobility of the mix and the particles smaller than $2.36 \mathrm{~mm}$ contributes to workability of the mix. Our aggregate gradations for all SCC spanned across three ranges defined above, indicating a combinations of strength, mobility and workability of mix.

As per Shilstone, concrete mixtures can be optimized using a relationship between a workability factor $(=\mathrm{W} /$ $(\mathrm{Q}+\mathrm{W}+\mathrm{I}))$ and a coarseness factor $(=\mathrm{Q} /(\mathrm{Q}+\mathrm{I}))$. According to him mixtures within the band shown in Fig. (2) are expected to be superior in terms of workability and will exhibit the lowest water demand for given cement content. But he developed the relationships for normal range of slump. The coarseness factor and workability factor from aggregate gradation for SCC mixtures used in our study are plotted in the Fig. (2). It is observed that the trend achieved by these five aggregate gradations is above the Shilstone's band and it is approximately parallel. This means as a starting point of SCC mix design, the aggregate gradation can be chosen in such a way that for a given CF, the WF should be above the band proposed by Shilstone and also the CF preferably be greater than 60 . However more data are required to finally recommend.

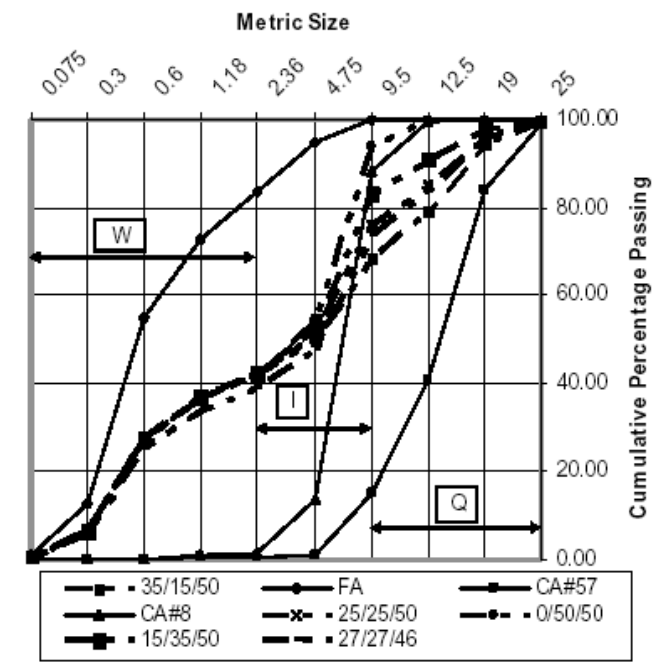

Fig. (1). Chart showing aggregate gradation.

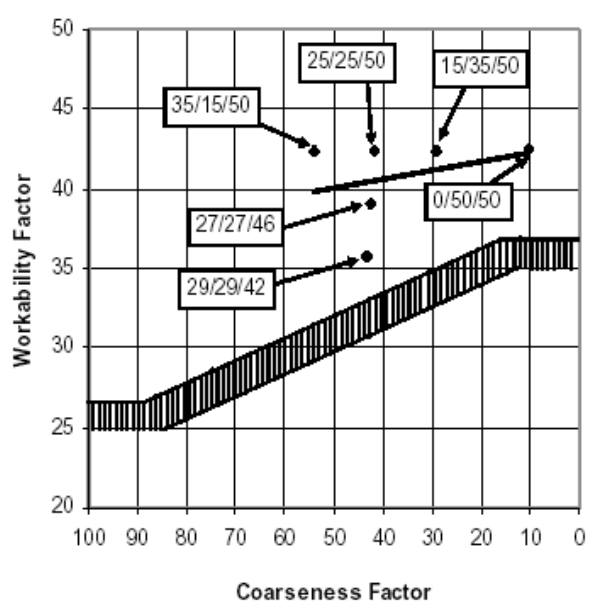

Fig. (2). Band of aggregate gradation on CF-WF chart.

\section{Comparisons of Fresh Properties}

Air content of all the mixtures were found to be between $6 \sim 7.5 \%$. Fig. (3), (4), and (5) represents the fresh properties achieved for the 10 SCC mixtures. Many international organizations such as RILEM, ACI, ASTM etc. has set some target limits for the fresh properties but those primarily depends on the type of application and acceptability of the concrete as SCC. Hwang et al. [14] proposed that SCC designed for structural applications should have a slump flow of 620 to $720 \mathrm{~mm}$, J-Ring flow 600 to $700 \mathrm{~mm}$ (Slump flow - JRing flow $\leq 50 \mathrm{~mm}$ ), L-Box blocking ratio (h2/h1) 0.7 and 
maximum surface settlement $\leq 0.5 \%$. Also, a combination of the slump flow and either the L-box blocking ratio (h2/h1), J-Ring, or V-funnel flow time can be used to assess filling capacity of SCC for placement in highly congested reinforcement typically encountered in structural applications. In this study the L-Box test was done with two bars. The target slump flow values for the mixtures were set to $650 \mathrm{~mm}$ as a minimum. The L-box test assesses the passing ability of SCC to flow through openings including reinforcing bars without segregation and blocking. Many researchers believe that there is a risk of blocking if the L-box ratio is less than 0.8 [15] but in contrary some of the report suggests that an Lbox blocking ratio of 0.6 is ample enough to obtain a good filling ability. In this study the target limit for L-box blocking ratio was kept at 0.7 . There is no specific threshold established for the column segregation test but $10 \%$ or less may be excellent in terms of segregation for the SCC [1] although a value of $15 \%$ is satisfactory as used in some projects [16]. In this experiment the target limit for column segregation was kept as $15 \%$.

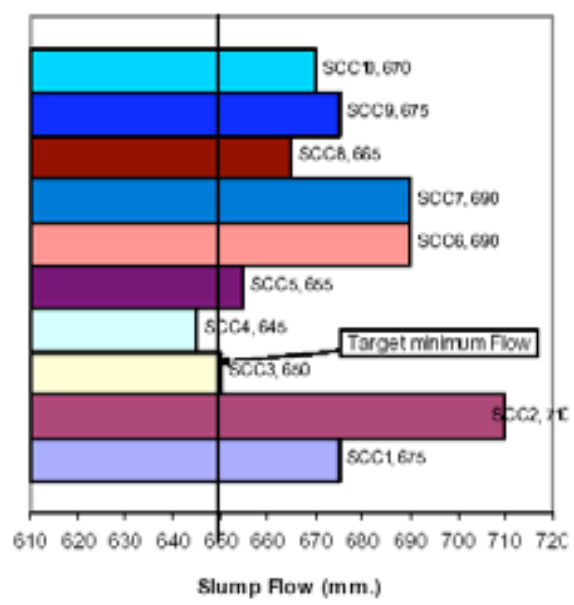

Fig. (3). Slump Flow values for 10 SCC mixtures.

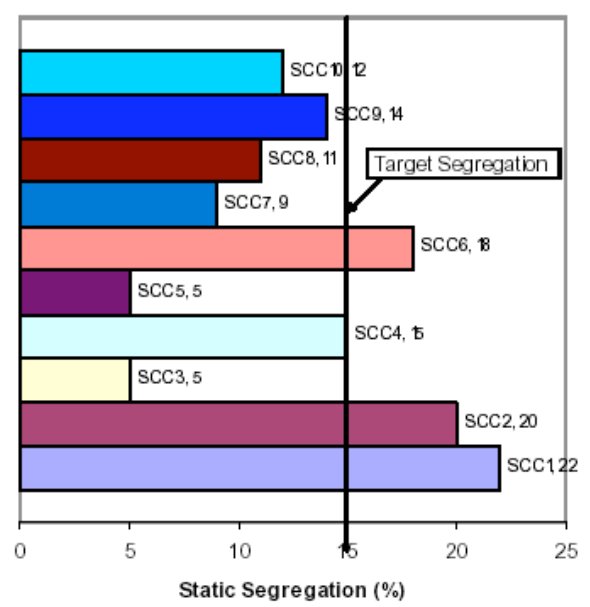

Fig. (4). Static segregation for the 10 SCC mixtures.

As observed from the results, the slump flow and L-box test results for almost all the SCC mixtures conformed to the target range. The highest slump flow value was obtained as $710 \mathrm{~mm}$ for SCC2. From the aggregate distribution point of view, it has been observed that more slump flow values were achieved when the two types of coarse aggregates (CA 25 $\mathrm{mm}$ and CA $9.5 \mathrm{~mm}$ ) were distributed evenly. For example, the maximum slump flow values of $710 \mathrm{~mm}, 690 \mathrm{~mm}$, and $690 \mathrm{~mm}$ were attained by SCC2, SCC6 and SCC7, respectively and their distribution of CA $25 \mathrm{~mm}$ and CA $9.5 \mathrm{~mm}$. were $25 \%-25 \%, 27 \%-0.27 \%$ and $29 \%-29 \%$, respectively of total aggregates. SCC4 had the least slump flow of $645 \mathrm{~mm}$. with a CA $25 \mathrm{~mm}$. percentage of $35 \%$ of total aggregate. The slump flow value of SCC4 could be increased by using more HRWRA compared to other mixtures. In general, all the SCC mixtures with different mineral admixtures and fillers, e.g., SL+SF, FA+SF and LP have shown consistent slump flow values, though mixtures containing LP have shown to produce more slump flow values compared to $\mathrm{SL}+\mathrm{SF}$ or $\mathrm{FA}+\mathrm{SF}$ mixtures. Between $\mathrm{SL}+\mathrm{SF}$ mixtures and $\mathrm{FA}+\mathrm{SF}$ mixtures, SL+SF mixtures have produced more slump flow than the FA+SF mixtures. More mixtures and tests needed to be done to support the facts. The L-Box passing ability results are consistent for all the SCC mixtures. SCC2 had the maximum passing ability of 0.95 followed by SCC1 which had a blocking ratio of 0.85 . Passing ability of all the other mixtures varied from 0.7 to 0.85 . For the L-box test also, it was noted that the passing ability of the mixtures containing LP were somewhat higher than the mixtures containing $\mathrm{SL}+\mathrm{SF}$ or $\mathrm{FA}+\mathrm{SF}$. Column segregation results were a little high for most of the mixtures. The highest static segregation values were found to be SCC1 followed by SCC2 and SCC6 with a segregation value of $22 \%, 20 \%$ and $18 \%$, respectively. It is to be noted here that generally the SCC mixtures with higher CA $25 \mathrm{~mm}$ displayed higher static segregation than the other mixtures. This was due to the use of higher coarse aggregate size fraction. This could be minimized and limited to $10-15 \%$ by using more VMA. The use of finer particles reduced the segregation values. In general, the segregation tendency was lower for all the mixtures produced with higher CA $9.5 \mathrm{~mm}$ fraction. Except for the mixture with $35 \%$ CA $9.5 \mathrm{~mm}$, the mixtures with LP showed higher static segregation than $\mathrm{SL}+\mathrm{SF}$ and $\mathrm{FA}+\mathrm{SF}$ mixtures. The $\mathrm{CF}$ or WF values obtained for different aggregate gradations did not have any correlations with slump flow or passing ability because for a given $\mathrm{CF}$ or WF, several slump flows or passing ability were possible by modifying the dosage of mineral and chemical admixtures.

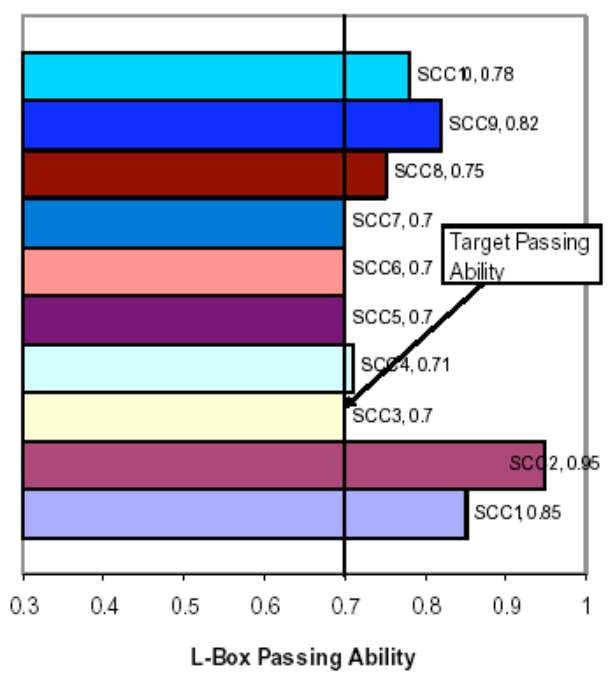

Fig. (5). Passing ability by L-Box for 10 SCC mixtures. 


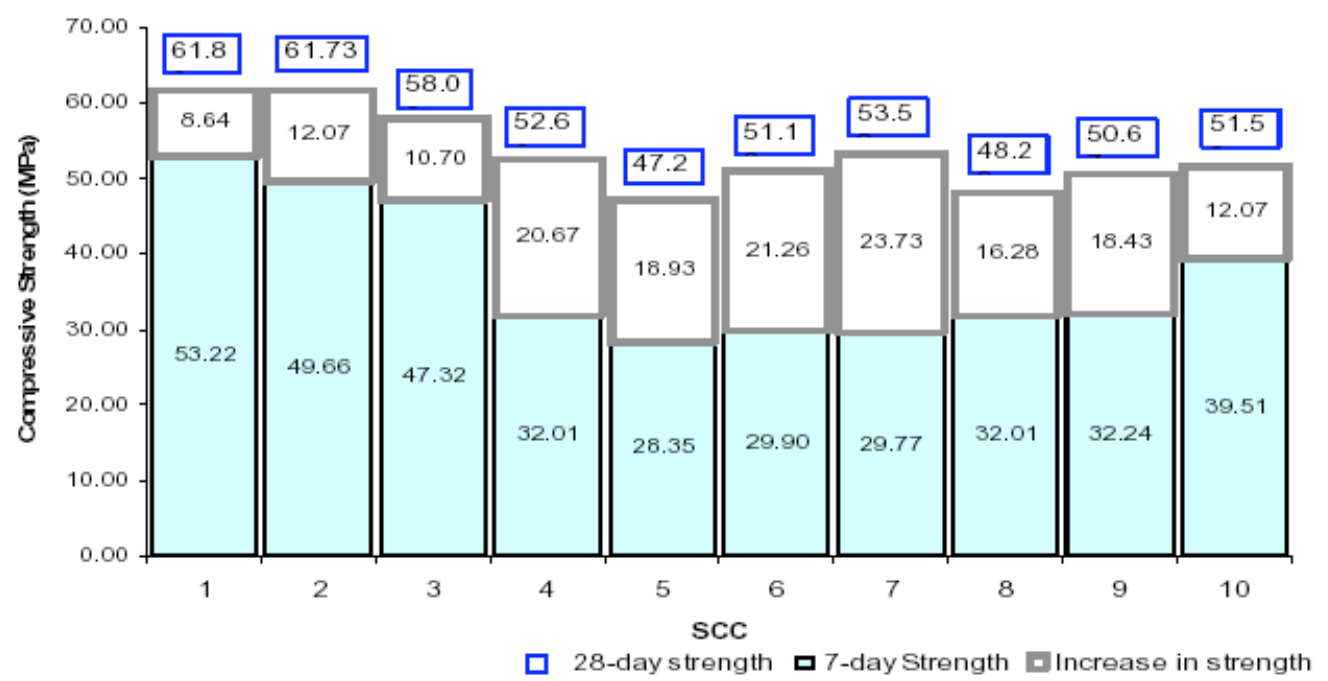

Fig. (6). 7-day and 28-day compressive strength for 10 SCC mixtures.

\section{Compressive Strengths and Correlations}

The compressive strength results (Fig. 6) show that mixtures containing limestone powder developed higher compressive strengths at both 7-day and 28-day compared to those mixtures with slag + silica fume or fly ash + silica fume. Similar observations have been made by Zhu et al. [17]. The SCC1 had the highest 28-day compressive strength among all the mixtures with a value of $61.8 \mathrm{MPa}$ followed by SCC2 and SCC 3 with values of 61.73 and $58 \mathrm{MPa}$, respectively. Mixtures with higher quantities of CA $25 \mathrm{~mm}$ developed higher compressive strength compared to mixtures with lower CA $25 \mathrm{~mm}$ content for SCC with LP. Similar trends had been observed for the mixtures containing $\mathrm{SL}+\mathrm{SF}$ and FA+SF. High early strength values were also observed for the mixtures with LP which were in the range of 47 53 MPa. Whereas the early strength of FA+SF ranged between 32 and $39 \mathrm{MPa}$ and for SL+SF mixture the range was between 28 to $32 \mathrm{MPa}$. It indicates that for given w/cm ratio, the early development of compressive strength was highest for mixtures with LP followed by mixtures with $\mathrm{FA}+\mathrm{SF}$ and $\mathrm{SL}+\mathrm{SF}$.

Paste volume is another important criterion for SCC as it is designed with a higher paste volume than normal concrete. Flowability of SCC increases with higher volume of paste but it may have detrimental effects on mechanical properties, time-dependent deformations and cracking susceptibility [18]. Paste volume of all the mixtures has been calculated as the total volume of all the mixture minus those from coarse and fine aggregates. The paste volumes were highest for the mixtures made with LP followed by the FA+SF mixtures. The paste volumes of the SL+SF were the least. The paste volume has been plotted against 7-day and 28-day compressive strengths in the Figs. (7) and (8). As seen from the figures, there exist definite correlations between compressive strength and paste volume for all the mixtures. Compressive strength was higher for the concretes made with higher paste volume. For example, SCC1 through SCC3 were made with highest paste volume of around 330 liters $/ \mathrm{m}^{3}$ of concrete and these three mixtures exhibited the highest 7-day and 28-day compressive strengths. Conversely, SCC 4 through SCC 7 made with lowest paste volume (varied between 300 312 liters $/ \mathrm{m}^{3}$ ) was characterized by low 7-day compressive strength compared to other mixtures, although the 28-day strengths were found to be better for SCC4, SCC6 and SCC7. As in this study the paste volume varied between $300 \mathrm{~L}$ and $330 \mathrm{~L}$, more strength data with wider range of paste volume are required to support the fact.

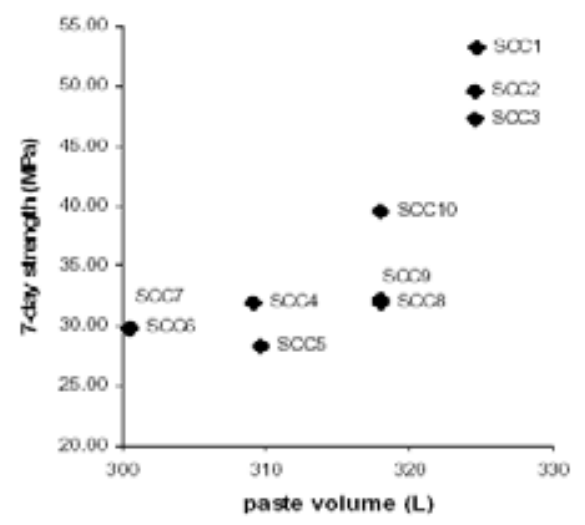

Fig. (7). Paste volume vs. 7-day compressive strength.

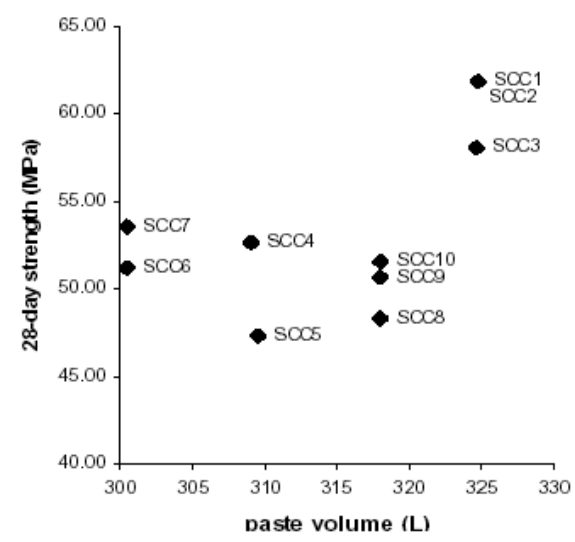

Fig. (8). Paste volume vs. 28-day compressive strength.

Fig. (9) and (10) represent the relationships between water-powder ratio (w/p) and compressive strength at ages 7- 
day and 28-day, respectively. The material of size $125 \mu$ or smaller were considered to be powder. As LP was a very fine filler material and was included in the powder calculation, the w/p ratio for SCC with LP was lowest and the value was 0.30 , whereas $\mathrm{w} / \mathrm{p}$ ratio for rest of the mixtures was around 0.39 . There is a definite trend between w/p ratio and compressive strength as evident from the figures with a regression co-efficient of 0.89 and 0.82 respectively. However due to strong influence of admixture on SCC, for a given w/p, different level of compressive strengths were possible. Though the $w / \mathrm{cm}$ ratios of all the mixtures were kept approximately same, the range of compressive strength varied greatly among the mixtures. This is due to the fact that the paste volume and powder content have significant effect on the compressive strength for the SCC.

Evaluations of Self-Consolidating Concrete

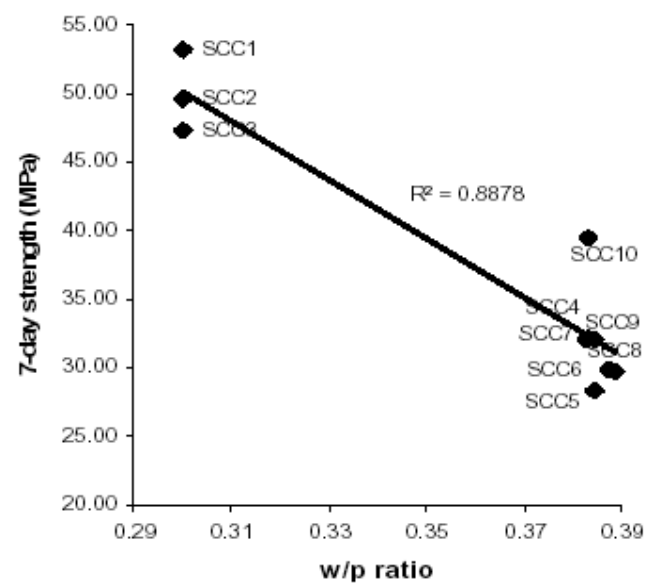

Fig. (9). W/p ratio vs. 7-day compressive strength.

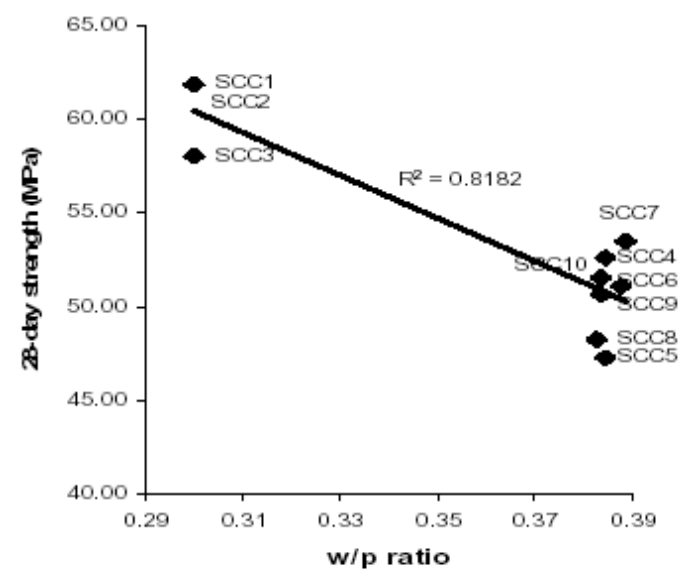

Fig. (10). W/p ratio vs. 28-day compressive strength.

\section{CONCLUSIONS}

The aggregate grading should pass through the three regions as mentioned in Fig. (1) and for a given CF, the WF should lie above Shiltston's band (Fig. 2). The equal distribution of $25 \mathrm{~mm}$ and $9.5 \mathrm{~mm}$ aggregate for SCC helped to achieve higher slump-flow. Limestone powder exhibited higher compressive strength compared to slag +silica fume and fly ash+ silica fume mainly due to lower water-powder ratio and higher paste volume which was found more important characteristics for SCC than water/cementitious materials ratio. Correlations exist between paste volume and waterpowder ratio with the compressive strength. In general it has been found that SCC properties are greatly influenced by admixture types and dosage, and filler. Further study on six selected mixtures on mechanical properties and cracking tendency estimation will reveal more information on hardened properties.

\section{ACKNOWLEDGEMENTS}

We gratefully acknowledge West Virginia Department of Transportation for their financial support; Jeff Stoker and Dr Van Bui of BASF for their valuable collaborations and technical advice, and Arrow Concrete Inc. and BASF for material donation.

\section{REFERENCES}

[1] ACI Committee 237. Self-Consolidating Concrete (ACI 237R-07) American Concrete Institute, Farmington Hills, Michigan, 2007.

[2] R. Gaimster and C. Foord, "Self-Compacting Concrete," Concrete, vol. 34(4), pp. 23-25, Apr. 2000.

[3] M. Ouchi, S. Nakamura, T. Osterberg, S.E. Hallberg, M. Lwin , "Applications of Self-Compacting concrete in Japan, Europe and The United States", Federal Highway Administration, 2003.

[4] J.M. Shilstone, "Concrete mixture optimization", Concrete International Journal, vol. 12(6), pp. 33-39, 1990.

[5] G. Heirman and L. Vandewalle,"The influence of fillers on the properties of Self-Compacting concrete in fresh and hardened state", in: Third International Symposium on Self-compacting Concrete. Reykjavik, Iceland, August, 2003.

[6] C.I. Goodier, "Development of self-compacting concrete", in: Proceedings of the Institution of Civil Engineers: Structures and buildings, pp. 405-414, 2003.

[7] Ghezal and K.H. Khayat, "Optimizing self-consolidating concrete with limestone filler by using statistical factorial design methods", ACI Materials Journal, vol. 99(3), pp. 264-272, 2002.

[8] H. Okamura and M. Ouchi, "Self-Compacting Concrete Development, Present Use and Future," Proceedings of the First International RILEM Symposium on SCC, pp. 3-14, 1999.

[9] M. Emborg and C. Hedin, "Production of Self-Compacting Concrete for Civil Engineering-Case Studies," Proceedings of the First International RILEM Symposium on SCC, Stockholm, Sweden, pp. 733, Sept. 1999.

[10] J.A. Daczko and E.K. Attiogbe, "Self-Consolidating Concrete, A Technology for the $21^{\text {st }}$ Century," Structural Engineer, Jan. 2003.

[11] J.A. Daczko and D. Constantiner, "Quality Control of SelfConsolidating and Rheodynamic Concrete," ACI Fifth International Conference, Supplementary Papers, Cancun, Mexico, Dec. 2002

[12] J.A. Daczko, "Stability of Self-Consolidating Concrete, Assumed or Ensured?" Proceedings of the First North American Conference on the Design and Use of SCC, Chicago, Ill., pp. 245, Nov. 2002.

[13] EFNARC, Test Methods-Annex B3, "The European Guidelines for Self-Compacting Concrete - Specification, Production and Use", web site: http://www.efnarc.org, May 2005.

[14] S.D. Hwang, K.H. Khayat and O. Bonneau, "Performance-based specifications of self-consolidating concrete used in structural applications", ACI Materials Journal, vol. 103(2), pp.121-129, 2006.

[15] B. Felekoglu, S. Turkel and B. Baradan, "Effect of water/cement ratio on the fresh and hardened properties of self-compacting concrete", Building and Environment Journal, vol. 42, pp. 1795-1802, 2007.

[16] http://www.dot.il.gov/desenv/pdf/80152.pdf [Accessed Dec. 5, 2007].

[17] W. Zhu and J.C. Gibbs, "Use of different limestone and chalk powders in self-compacting concrete", Cement and Concrete Research Journal, vol. 35, pp. 1457-1462, 2005. 
[18] E. Roziere, S. Granger, Ph. Turcy and A. Loukili, "Influence of paste volume on shrinkage cracking and fracture properties of self- compacting concrete", Cement \& Concrete Composites Journal, vol. 29, pp. 626-636, 2007.

Received: March 27, 2008

Revised: April 28, 2008

Accepted: May 30, 2008

(C) Bhattacharya et al.; Licensee Bentham Open.

This is an open access article distributed under the terms of the Creative Commons Attribution License (http://creativecommons.org/licenses/by/2.5/), which permits unrestrictive use, distribution, and reproduction in any medium, provided the original work is properly cited. 